\title{
FACEWORK AND GESTURES: A PRELIMINARY ANALYSIS OF THE COMMUNICATIVE POWER OF HUMAN PERFORMATIVE NON-VERBAL PRACTICES
}

\author{
JOANNA PUPPEL
}

All the world's a stage, and all men and women merely players William Shakespeare, As you like it, Act II, Scene VII

\section{Introduction}

Human facework and human gestures are an important part of daily communicative practice in human-human encounters. By assisting in verbal message communicative efficiency, they form a distinct communicative design. It is, therefore, tempting to look at this complex communicative non-verbal 'faceworkgesture design' (hence FGD) from the point of view of assigning to it the status of the most expressive part of human performativity. The latter term is assumed to belong to the 'performative turn' in communication research which focuses on the joint power of verbal, bodily and multi-modal performances accomplished in the public space.

Further, it is assumed that performance is a form of an act of display performed in front of an audience or together with an audience. As Goffman defined it (1969: 19), it is "all the activity of an individual which occurs during a period marked by his continuous presence before a particular set of observers and which has some influence on the observers". In addition, it may be defined as a show or a happening, "a showing of a doing" as Grimes would express it 
(Grimes 2003: 35). This showing by doing is accomplished publically, that is, in the necessary surrounding of the audience which is also assumed to contribute both to the performance's efficiency and its social meaningfulness (cf. Robinson 2006).

In turn, the performative turn in communication studies referred to above derives from the seminal work of Austin $(1962,1970)$ and represents a radical shift in research methodology from focus on the analyses of various linguistic phenomena within the paradigm of mental representation, developed so intensively in the second half of the XXth century in such subdomains of linguistics as psycholinguistics and, generally, the entire area of cognitive studies, to the "performative' paradigm and 'performative' research methodology focused on analyses of linguistic and non-linguistic phenomena understood as part of human performance. The latter is meant as a social act rather than as an which is based exclusively on (and accounted for by) the presence of the human mental dimension. That is why the term 'performativity', as constituting the core of performance studies (cf. Schechner 2006), is preferred in this brief analysis of the communicative efficiency of the human FGD. It must be added, however, that the paradigm of mental representation is not hereby nullified, for its important contribution to the study of human communication (i.e. communicology, see Puppel 2008) is fully acknowledged here. The paper may thus be regarded as belonging to a dynamically developing domain of performative studies, or, more precisely, to the area which focuses on performative non-verbal human practices in human communication.

In addition, within the human body a distinction is made as regards the presence of different FGD performative topographies. The following topographies are distinguished:

- the performative topography of the human facial domain $(\mathrm{F})$,

- the performative topography of the human gestural domain $(\mathrm{G})$, and

- the performative blended topography of the entire FGD.

It is further assumed that the particular performative topographies display different communicative power, or, that they demonstrate different potentials for expressing different degrees of affect in human communicative practice. Simply, it is assumed that the topographies represent different degrees of performativity (or they demonstrate different performativity index). In this sense, they represent different 'emotional topographies' (cf. Puncer 2011). In the present account, the performative topography of the synergistic and blended type, that is, of the entire FGD, is regarded as the most optimal, most powerful and, therefore, most efficient. As a result, the FGD is regarded here as the seat of human emotional 'politics' which is applied in various proportions in diversified performative acts. It is on this design that the communicator's performative non-verbal competence is based. 
The FGD can be shown by means of the following schematized drawing:

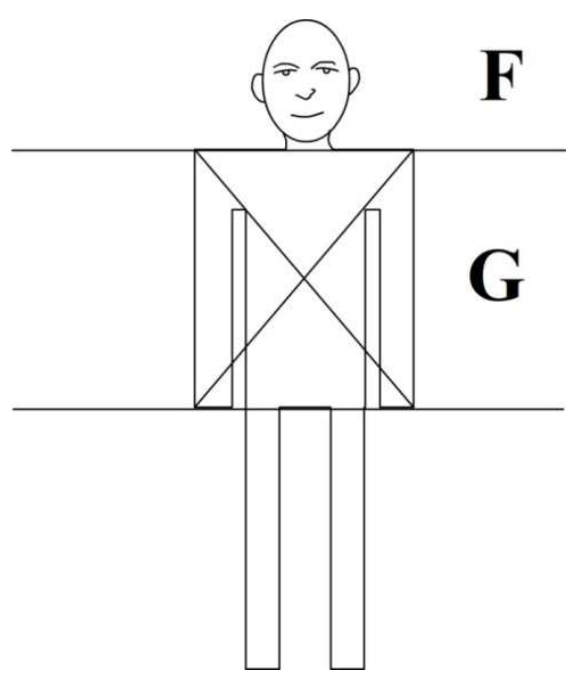

Fig. 1. The facial-gestural design (FGD)

Where:

$\mathrm{F}-$ the human facial domain

$\mathrm{G}$ - the human gestural domain

$\mathrm{X}$ - the crossed lines on the chest represent the kinetic potential of the human hands

${ }_{-}$- the horizontal lines serve to separate the domains.

\section{The performative topography of the human facial domain (F)}

As indicated by the results of various studies conducted in the facial domain, this domain, which is located in the top section of the human body (see Fig. 1 above) and which comprises the human face, is the one by means of which such basic human emotions as joy, surprise, fear, anger, sadness, and disgust are expressed in the most pronounced way. F may, therefore, be assumed to be the center of the emotionally-driven performative topography of the human body. It is also with reference to this domain that the particular members of the audience (i.e. both the observers and participants in communicative acts) in the sense described above are able to recognize emotions across the entire human species and across the human local cultures (cf., for example, Russell 1994; Schmidt and Cohn 2002; and an extremely useful and comprehensive study edited by Ekman 2006; Puppel 2011, and the literature cited therein). In this paper, an assumption is made that the $\mathrm{F}$ domain provides a strong index of performativity. 


\section{The performative topography of the human gestural domain (G)}

The gestural domain, located in the middle section of the human body (see Fig. 1 above) and which comprises the hands, is the one by means of which a considerable array of gestural (bimanual) movements are performed so that quite a number of discrete gestural operations are carried out by the communicators in the service of non-verbal communication basically supporting the verbal communicative behavior (cf. e.g. McNeill 2000). It is assumed that the G domain, treated separately, is the weakest in the terms of the performativity index.

\section{The performative topography of the entire human facial-gestural domain (FGD)}

The performative topography of the entire human facial-gestural domain (FGD) is the largest of the three and it comprises the facial and gestural domains combined together (as shown in Fig. 1 above). In the paper, an assumption is also made that the combined facial-gestural complex due to its mixed (blended) nature is the most powerful domain in terms of its performativity index. In order to check the above assumptions, a questionnaire was administered and the results obtained were presented.

\section{Materials and research procedure}

The research data were collected from 31 anonymous respondents who participated in a brief survey administered via the Web page www.ankietka.pl. In the survey, the respondents were asked to indicate the performativity index of the particular performative topographies on a two-point dichotomous scale ranging from the 'least effective use' of the respective topographies to the 'most effective use' of the said topographies. The proposed scale ranged from the value ' 1 ', representing the weakest degree of performativity, to the value ' 5 ' which represented the highest degree of performativity. The survey provided the following results:

(a) performativity index of the performative topography of the human facial domain $(\mathrm{F})$ :

The respondents indicated their choices in the following way:

- the value ' 1 ' (the least effective use) was indicated in the total of $70,97 \%$

- the value ' 5 ' (the most effective) was indicated in the total of $29,03 \%$. 
(b) Performativity index of the performative topography of the human gestural domain $(\mathrm{G})$ :

- the value ' 1 ' was indicated in the total of $72,32 \%$

- the value ' 5 ' was indicated in the total of $9,68 \%$.

(c) Performativity index of the performative blended topography of the entire human facial-gestural design (FGD):

- the value ' 1 ' was indicated in the total of $35,48 \%$

- the value ' 5 ' was indicated in the total of $64,52 \%$.

The contributions of the respective topographies with respect to the highest degree of their overall effectiveness in human non-verbal communicative practices is shown below.

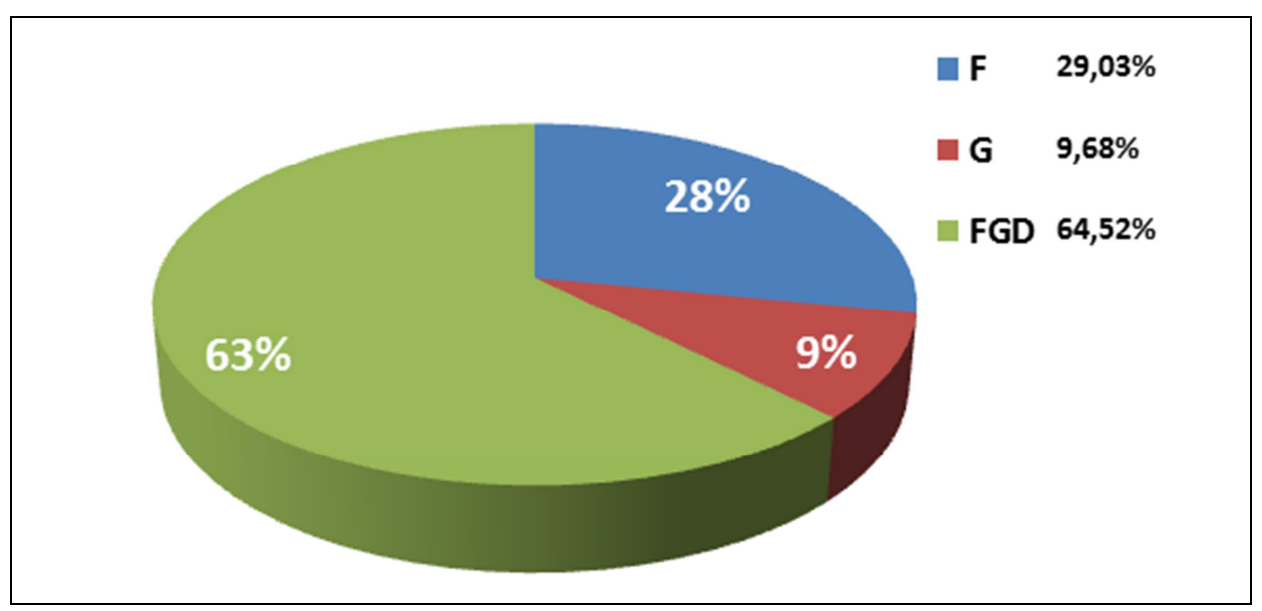

Fig. 2

\section{Conclusions}

As was indicated by the results of the survey, the three topographies may be tentatively characterized as demonstrating different degrees of communicative power. The results may thus prompt one to suggest that the performative powers of the topographies are distributed in the following way:

(a) the weakest performative power is demonstrated by G,

(b) the medium-ranged performative power is demonstrated by $\mathrm{F}$,

(c) the greatest performative power is demonstrated by the FGD.

The results of the present pilot study may be used as providing some evidence concerning the most effective use of the entire FGD by the human communicators in the public space. They may also serve to indicate that the commu- 
nicative competence of every human communicator comprises an intricate control of the performativity index of the entire FGD, with special focus on the dominant performative power of the entire human facial-gestural design.

\section{References}

Austin, J.L. 1962. How to do things with words. Oxford: Clarendon Press.

Austin, J.L. 1970. "Performative utterances". In: Austin, J.L. Philosophical papers. Oxford: Oxford University Press. 233-252.

Ekman, P. (ed.). 2006. Darwin and facial expression: a century of research in review. Cambridge, Mass.: Malor Books.

Goffman, E. 1969. The presentation of self in everyday life. London: Allen Lane The Penguin Press.

Grimes, R.L. 2003. "Ritual theory and the environment". In: Heim, W., Szerszynski, B. and C. Waterton. (eds.). Nature performed: environment, culture and performance. Oxford: Blackwell. 31-45.

McNeill, D. (ed.). 2000. Language and gesture. Cambridge: Cambridge University Press.

Puncer, M. 2011. "Emotional topographies of performative artistic practices". Art, emotion and value. $5^{\text {th }}$ Mediterranean Congress of Aesthetics, 2011. 409-420.

Puppel, J. 2011. „Uwagi w sprawie zarządzania twarzą w przestrzeni publicznej”. In: Puppel, S. (ed.). Transkomunikacja. W stronę sprofilowania przestrzeni publicznej jako wielopłaszczyznowej przestrzeni komunikacyjnej. Poznań: Katedra Ekokomunikacji UAM. 81-89.

Puppel, S. 2008. "Communicology: remarks on the reemergence of a paradigm in communication studies”. In: Puppel, S. and M. Bogusławska-Tafelska. (eds.). New pathways in linguistics 2008. Olsztyn: Uniwersytet Warmińsko-Mazurski. 11-22.

Robinson, D. 2006. Introducing performative pragmatics. London: Routledge.

Russell, J. 1994. "Is there universal recognition of emotion from facial expression? A review of the cross-cultural studies". Psychological Bulletin 115. 102-141.

Schechner, R. 2006. Performance studies: an introduction. London: Routledge.

Schmidt, K. and J. Cohn. 2002. "Human facial expressions as adaptations: evolutionary questions in facial expression". Yearbook of Physical Anthropology 44. 3-24. 